\title{
The cooling and heating research of an underground water source heat pump system in Qian'an \\ Bin Yang ${ }^{1, a^{*}}$, Yashuai Yang ${ }^{2, b}$ and Degong Zuo ${ }^{3, c}$
}

\author{
${ }^{1}$ School of Energy and Environment Engineering, Hebei University of Technology, China \\ ${ }^{2}$ School of Energy and Environment Engineering, Hebei University of Technology, China \\ ${ }^{3}$ School of Energy and Environment Engineering, Hebei University of Technology, China \\ a yangbin0720@126.com, b 953359943@qq.com, ${ }^{c} 1123550491 @ q q . c o m$
}

Keywords: water source heat pump. operation performance. benefit analysis

Abstract. In recent years, the promotion of renewable energy has been used in many Qian'an's buildings, and in which the use of groundwater source heat pump technology is particularly widespread. This work is focused on the comprehensive economic analysis and energy efficiency evaluation of groundwater source heat pump system for a building in the Qian'an City. As the data analysis shown, we can see that the summer average COP is 2.46 and that of winter is 2.27. Meanwhile, the load fluctuations of the day's operating parameter are relatively stable. In combination with engineering example analysis of factors influencing the operating efficiency, it is concluded that should be adopted "large temperature difference, small flow" operation mode, the comprehensive analysis to get the best combining site. Through this research, the author hopes to further enhance the energy conserving potential of the underground water source heat pump system in Qian'an region to provide important data basis, and operation and management of the maintenance of the relevant system has a certain engineering guidance.

\section{Introduction}

With the rapid economic development and people's living standards improve, urbanization and modernization process will continue to accelerate and the construction area is also expanding. In the Public buildings and residential, air-conditioning in summer and heating in winter has become a widespread need. At present, China's energy consumption in buildings accounted for nearly $30 \%$ of total energy consumption society, but also to more than $1 \%$ per year growth rate. If not controlled, in accordance with the law of development of the Western developed countries, to 2020 will occupy total energy consumption by more than $40 \%^{[1]}$. Meanwhile, the pressure facing resources and environment will also be growing. Building energy consumption has been called three "energy-hungry" with the industrial energy consumption, transportation and consumption of energy consumption $^{[2]}$.

Groundwater source heat pump system as a kind of high efficiency, energy-saving and environmentally friendly technology in recent years, more and more get the people's attention. At the same time, its practical application has also been rapid development. According to the relevant departments of the prediction, the technology will become the 21 st century the most efficient heating and cooling technology ${ }^{[3]}$.

\section{Introduction of water source heat pump system}

As natural phenomenon, the water can spontaneously flow from high to low, the heat can also by the high temperature side flow to the low temperature side. In real life, people use water pump by entering a certain amount of electricity power, the water from the lower lift to high, in the same way, also can use heat pump technology, the heat from low temperature side to the high temperature side.

Therefore, heat pump lifting equipment can be regarded as a kind of energy, It pump out environmental media to increase the temperature through part of electric energy consumption of 
energy. however, the heat pump device consumes only a third or more quantity of heat low, so the heat pump has the characteristics of energy saving.

Principle of water source heat pump is the use of heat pump, through the consumption of a small amount of electrical energy, It can make full use of the surface of shallow geothermal energy, such as soil, groundwater or surface water (river, sea, river, lake, or shallow pool) in the absorption of solar and geothermal energy and formation of the low heat, and low heat energy to a high heat energy conversion technology. In summer, the refrigerant absorbs heat evaporation, and remove the heat from conditioned room to put in the water source. In winter, refrigerant in the evaporator evaporates, and the heat in the water is absorbed, rear-load refrigerant condensing heat to raise the temperature, so as to enhance the temperature of air-conditioned room. Figure 1 is water source heat pump system works ${ }^{[4]}$.

Water source heat pump central air conditioning system generally consists of three parts: the end system, water supply central air-conditioning host system and water supply system ${ }^{[5]}$.

\section{Project operation efficiency analysis}

Project summary. This study is a Fortune Center in Qian'an, the project demonstration area of $59000 \mathrm{~m}^{2}$, the use of groundwater source heat pump system for the building to achieve heating / cooling function. The building belongs to the comprehensive construction, including office and residential, so it has great value in research. The research data from the high zone heat pump system, and the high area is mainly used for hotel, office and residential.

The project chooses 4 McQuay water source heat pump units, including two McQuay WPS430.3 C whose cooling/heating are $1628.6 \mathrm{~kW}$ and $1421.8 \mathrm{~kW}$ for low district heating/cooling unit, and two McQuay WPS300.2C unit whose cooling / heating are $1116.2 \mathrm{~kW}$ and 973.9kW belong to high heat pump system. The system also use $1 \mathrm{McQuay}$ WPS135.1C to provide domestic hot water, and the heat capacity are $435.6 \mathrm{~kW}$. Units use $\mathrm{R} 134 \mathrm{a}$ refrigerant and can be uninstalled according to the actual running load in order to save energy. Water-side configuration: 10 water wells; effective depth of 60 meters; in tube diameter $600 \mathrm{~mm}$; single-mouth out of water $200 \mathrm{~m}^{3} / \mathrm{h}$.

\section{The data processing.}

The average coefficients of the system is calculated as:

$$
C O P=\frac{Q}{N_{1}+N_{2}}
$$

Where: $Q$-- end of the cold / heat load, $\mathrm{kW} ; N_{1}, N_{2}$-- respectively unit and circulating pump power, $\mathrm{kW}$.

At the end of the cold heat calculation:

$$
Q=\frac{\rho_{W} c G_{W} \Delta t_{W}}{3600}
$$

Where: $\rho_{W}$-- water density, $\mathrm{kg} / \mathrm{m}^{3} ; G_{W}$-- circulation flow, $\mathrm{m}^{3} / \mathrm{h} ; \Delta t_{W}$-- import and export temperature difference; $c$-- water specific heat, $\mathrm{kJ} /(\mathrm{kg} \cdot \square)$. 


\section{The data analysis.}

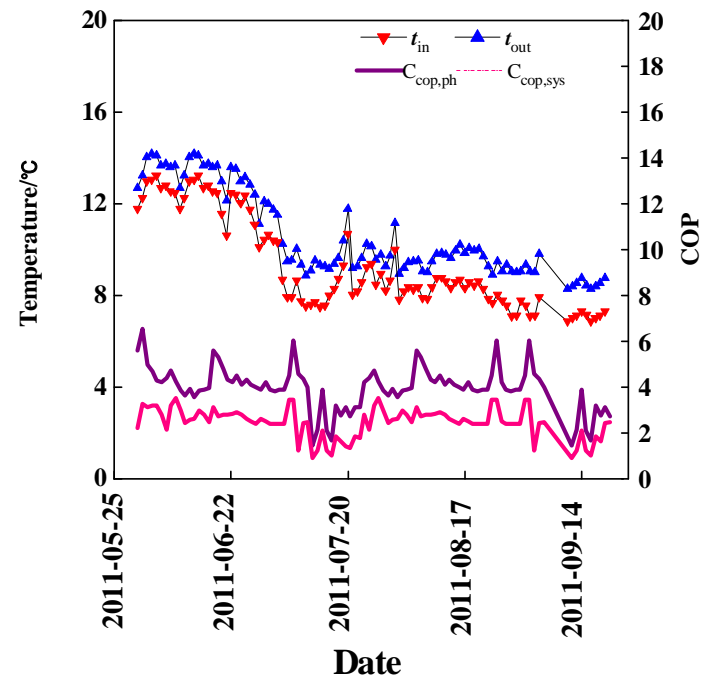

Fig1 Changes of COP and temperature in summer

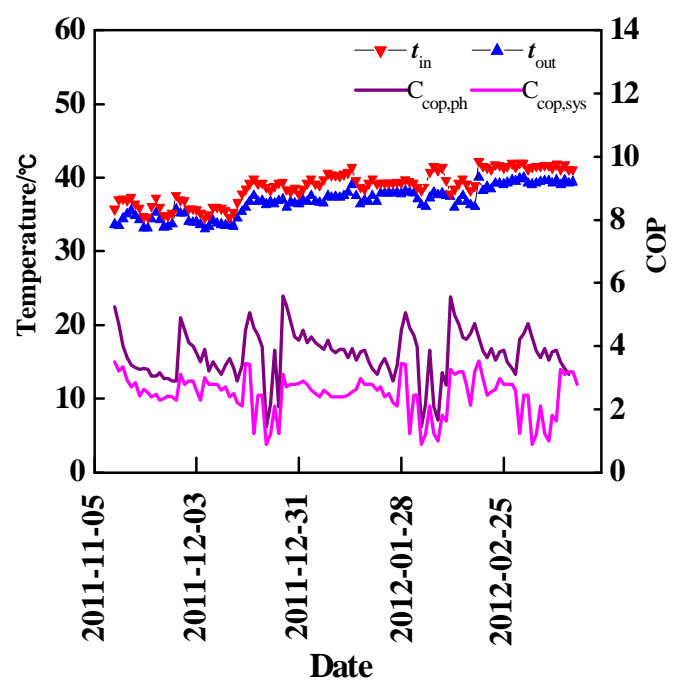

Fig2 Changes of COP and temperature in winter

Through the figure 1 can be analyzed in the summer of 2011 the system running parameters. As the weather is getting hot, indoor cooling load is bigger and bigger, and the water supply in the system was decreased in the temperature to meet the demand of people's life. The average system's $\mathrm{COP}$ is 2.46. Also, figure 2 is 2011 winter running parameters of the system. It can be seen that as the weather got cold, indoor heat load increased, and the water temperature in the system gradually rise to improve the indoor thermal comfort. The average system's COP of winter is 2.27.

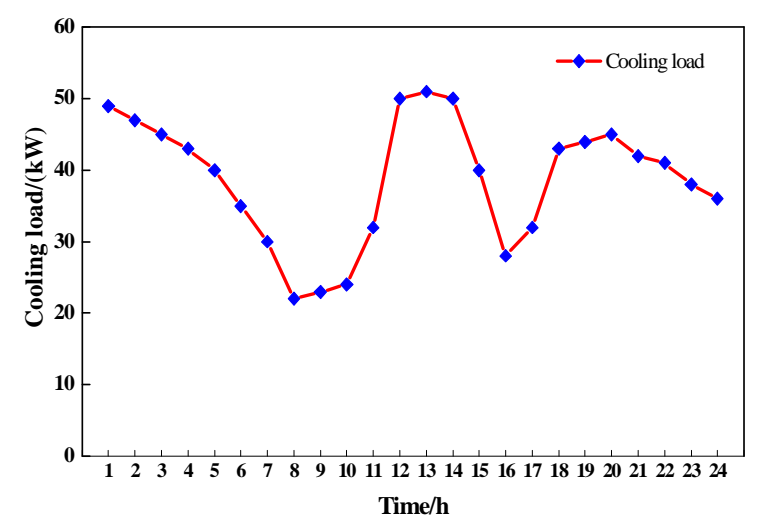

Fig3 Office building of typical day hourly air conditioning cooling load in summer

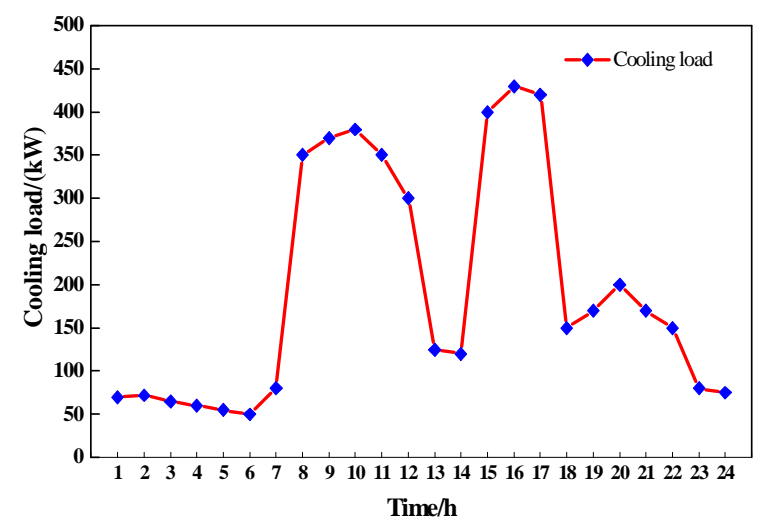

Fig4 Residential typical day hourly air conditioning cooling load in summer

The project is a comprehensive architecture which obtain both residential and office there. Figure 3 and Figure 4 are typical of office and residential summer cooling load changes.

Office building air conditioning load growth appeared at 7:00 in the morning, the staff off work, the office building each room open air conditioning. Considering the temperature is relatively low in the morning, and with the augmentation of the solar radiation, peak cooling load to 9:00. With the operation of the air conditioning system, temperature in each room of the building is reduced, and indoor will grow a certain amount of cold storage. Until 12:00 noon go off work, part of the room air conditioning closed, and the air conditioning load reach trough value. after work in afternoon, air conditioning open again, another air conditioning cooling load reached the peak. Once again at this time because of strong solar radiation in the afternoon and outdoor air temperature is high, so the air conditioning cooling load is relatively high.Also, as the operation of the air conditioning system, indoor cold quantity of reserves, air conditioning cooling load is reduced, until the afternoon after work, cooling load to trough value again. 
The cooling load of residential mainly concentrate between 20:00 to 7:00, because this time people mainly in indoor activities. Taking into account the structure and thermal properties of the room building envelope, the peak may be with respect to the solar radiation heat gain peak in time there is a delay, and there is amplitude attenuation. At 7:00, the outdoor temperature is low, and taking into account the staff work, the cooling load is small. In contrast, the maximum cooling load occurs at about 13:00 pm, after people get home from work, plus noon outdoor air temperature is higher, the cooling load reaches a maximum within a day.

The project is a comprehensive building, considering the two functions - residential and office buildings, cooling load only appeared two big fluctuations, respectively is noon and afternoon two hours after work. And at 7:00 PM in the evening until morning, during the most users in indoor activities, cooling load relative to work time is lesser, and relatively stable .

\section{Conclusion}

Taking Qian'an region wealth center water source heat pump engineering as an example, through analyzing the operation monitoring data processing can get the following conclusions:

(1) Using the theory of learned knowledge, such as engineering thermodynamics, refrigeration technology to analyse the energy-saving heat pump system. It is concluded that water source heat pump system is energy saving technology, and its performance coefficient is higher than air source heat pump.

(2) analysis of operational data processing by drawing can get summer average of COP is 3.41 and that of winter is 2.67. Meanwhile, as an integrated architecture, the load fluctuations of the day's operating parameter are relatively stable.

(3) with an engineering example analysis of factors affecting the operation of the energy efficiency, the influence of water temperature and water flow rate on the system efficiency, the results should be used "big temperature difference and low flow" mode of operation, a comprehensive analysis of the optimal combination of points.

In summary, the water source heat pump system is a new type of air-conditioning systems, has significant environmental and economic benefits. Through this research, hoping to provide an important basis for further enhanced data Qian'an groundwater source heat pump system energy-saving potential, for the operation and management related to system maintenance has a guiding role.

\section{Acknowledgement}

This work was financially supported by National Major Project of Scientific and Technical Supporting Programs of China during the 12th Five-year Plan Period (Grant No. 2012BAJ06B04), the Research Program of Construction Technology in Hebei province(Grant No.201522JS), the project of 2015 Tianjin Technological Innovation to guide specially outstanding Science and Technology Correspondent, Tianjin Education Commission Scientific Research project(Grant No. 20140418).

\section{References}

[1] Rui Wang, Wenwu Song, Mei Liu, Dengsong Li. The economic analysis and application of water source heat pump air conditioning system, J. Building technology at low temperature,2013,12:137-139.

[2] Chong Lu, Juan Liu. Guilin star hotels central air conditioning energy conservation and emissions reduction research--heat pump technology application feasibility analysis, J. Value engineering, 2010,20:101-103.

[3] Fang Wang, Xiaowei Fan, Guanghui Zhou, Zhiwei lian. The current research on water source heat pump in China, J. Fluid machinery, 2003,04:57-59.

[4] Dongli Fan. The world's energy status and the future, J. Metal heat treatment, 2011,10:119-131. 
[5] Dong Liu. The economic analysis and the application of water source heat pump, D. Tianjin university, 2004. 